\title{
Functional Outcomes of Intravenous Thrombolysis in Octogenarians and Nonagenarians Through Telestroke: Single-Center Experience
}

Tarun Girotra, $M D_{1}^{1}$ Eyad Almallouhi, $M D_{1}{ }^{2}$ Sami Al Kasab, $M D_{1}^{3}$ Chirantan Banerjee, $M D_{1}^{2}$ Nancy L. Turner, BSN, RN, CPAN, ${ }^{4}$

Ellen Debenham, RN, CCRC, ${ }^{4}$ and Christine Ann Holmstedt, $D O^{2}$

${ }^{1}$ Department of Neurology, University of New Mexico, Albuquerque, New Mexico.

${ }^{2}$ Department of Neurology, Medical University of South Carolina, Charleston, South Carolina.

${ }^{3}$ Department of Neurology, University of lowa, lowa City, lowa.

${ }^{4}$ Department of Telehealth, Medical University of South Carolina, Charleston, South Carolina.

\section{Abstract}

Background: Patients aged $\geq 80$ years are often underrepresented in stroke trials. Observational studies have shown that older patients have worse outcomes compared with younger patients, but outcomes in patients aged $\geq 80$ years treated with intravenous (IV)-alteplase specifically through telestroke (TS) have not been studied.

Aim: To compare clinical and safety outcomes in stroke patients aged $\geq 80$ and 60-79 years treated with IV-alteplase via TS.

Methods: The Medical University of South Carolina TS database was analyzed to identify $I V$-alteplase-treated patients aged 60-79 and $\geq 80$ years between January 2015 and March 2018. Baseline demographics and TS-specific variables were compared. Clinical outcomes were assessed using the 90-day modified Rankin Scale (mRS). Safety outcomes were evaluated by comparing symptomatic intracranial hemorrhage (sICH). Multivariate logistic regression analysis was performed to determine odds ratio (OR) for good outcome ( $m R S$ $0-2)$ in the older age group at 90 days.

Results: IV-alteplase was used in 151 patients in $\geq 80$ years age group and 273 patients in 60-79 years age group. The older age group had more women and a higher National Institutes of Health Stroke Scale. The mean "ED-door-to-TSconsultant-login" time was shorter $(21.6 \mathrm{~min}$ vs. $25.6 \mathrm{~min}$; $\mathrm{p}=0.048$ ), but "TS-consultant-login-to-alteplase" time was longer (22.1 $\mathrm{min}$ vs. $19.3 \mathrm{~min} ; \mathrm{p}=0.01)$ in the older age group. No difference was noted in eventual "door-to-needle" time. The older age group had fewer good outcomes $(39.1 \%$ vs. $74 \% ; \mathrm{p}=0.001)$ and more deaths (38\% vs. $14 \% ; \mathrm{p}=0.001)$ at 90 days. The sICH rates were similar in the two groups. The $O R$ for good outcome in $\geq 80$ years age group was 0.20 (95\% CI: 0.12-0.34) after controlling for baseline variables.

Conclusions: Stroke patients aged $\geq 80$ years treated via TS have similar post-thrombolysis hemorrhage rates but worse clinical outcomes compared with patients aged 60-79 years.

Keywords: teleneurology, telestroke, telemedicine, emergency medicine/teletrauma, cardiology/cardiovascular disease

\section{Background}

he incidence of stroke increases with age and is particularly high in octogenarians and nonagenarians. ${ }^{1}$ Despite this, patients older than 80 years are often excluded or significantly underrepresented in randomized clinical trials studying the effects of various interventions for acute ischemic stroke treatment. We know that outcomes in octogenarians and nonagenarians are worse compared with younger age cohorts based on observational studies across the United States and Europe in which intravenous (IV)-alteplase was administered after a traditional face-to-face evaluation of the patients by a neurologist. ${ }^{2-4}$

Telestroke (TS) has emerged as an essential modality to provide acute stroke care to patients in rural and small community hospitals. ${ }^{5-7}$ The overall safety profile of IV-alteplase administration via TS has been established, and the postthrombolysis symptomatic hemorrhage rates are similar to the rates noted when patients are treated with IV-alteplase in the traditional setting. ${ }^{8,9}$ These studies, unfortunately, have underrepresented patients older than 80 years. There is even more dearth of data regarding functional outcomes in elderly patients treated with IV-alteplase after remote evaluation via TS. The elderly population is at higher risk of symptomatic intracranial hemorrhage ( $\mathrm{sICH}$ ) and hence poorer outcomes compared with younger patients; therefore, there is an urgent need to assess the safety and functional outcomes in elderly patients treated for acute stroke over TS.

The goal of this study was to assess the above-mentioned safety and functional outcomes in patients aged $\geq 80$ years treated with IV-alteplase via TS at the Medical University of South Carolina (MUSC) Health TS program and compare these outcomes with patients aged between 60 and 79 years. 


\section{OUTCOMES IN ELDERLY OVER TELESTROKE}

\section{Methods}

\section{PATIENTS AND BASELINE VARIABLES}

The MUSC Health TS program started in 2008 to provide expert stroke care to remote hospitals in South Carolina (SC). ${ }^{6,10,11}$ Over the past 10 years, the TS program has expanded and now covers 28 hospitals across the state of SC. The MUSC Health TS database is a prospectively collected quality improvement database. The database was retrospectively analyzed from January 2015 to March 2018 for patients aged $\geq 60$ years and received IV-alteplase after evaluation by TS neurologist for stroke-like symptoms. The cohort was dichotomized to $60-79$ and $\geq 80$ years age groups. SC lies within the "stroke-belt" and has a higher proportion of the young and middle-aged population affected by stroke compared with national average. ${ }^{12}$ To avoid potential bias by the inclusion of younger patients in our study, the population younger than 60 years was excluded from the analysis. Baseline variables including age, gender, National Institutes of Health Stroke Scale (NIHSS) on presentation, and TS-specific time variables were collected. The TS-specific time variables included "ED door to TS consult page," "TS consult page to TS consultant login," "TS consultant login to alteplase decision," and "alteplase decision to administration" times. The eventual "door to needle" time and the final diagnosis of "stroke vs. strokemimic" were also obtained from the database.

\section{OUTCOMES}

Primary clinical outcome was assessed using the modified Rankin Scale (mRS) at 90 days. The mRS is a 7-point scale ranging from 0 (no symptoms) to 6 (death), with the score of 0-2 indicating functional independence ("good outcome"). Primary safety outcome included sICH post-IV-alteplase (defined per the National Institute of Neurological Disorders and Stroke [NINDS] criteria as any hemorrhage on computed tomography [CT] scan within $36 \mathrm{~h}$ of thrombolysis with NIHSS increase by at least 1 point) and asymptomatic intracranial hemorrhage (aICH) (defined as hemorrhage on CT scan without any neurological worsening). Discharge disposition was also analyzed from the database. The NINDS criteria for sICH were the standard and most commonly utilized definitions of post-thrombolysis sICH when the MUSC TS program was initiated in 2008. To ensure that spoke sites continue to provide consistent reports of sICH, the NINDS criteria continued to be used in the MUSC TS database for the definition of sICH.

The safety outcome data were collected by the MUSC Health TS program coordinators either by chart review of the patient admitted to the MUSC and its affiliated sites or by a telephonic conversation with the stroke coordinator of the treating hospital. All patients receiving IV-alteplase were called by the
MUSC Health TS coordinator 90 days after stroke to determine their functional status and to assign mRS. Three attempts were made to get in touch with each of the patients to determine their 90-day mRS.

\section{STATISTICAL METHODS}

Patient variables were described as means with standard deviation for continuous variables, and frequencies and percentages for categorical variables. All analyses were twotailed and performed at a significance level of 0.05. Fisher's exact test was used to compare categorical variables, and $t$ test was used to compare continuous variables between the two groups. Multivariate logistic regression analysis was performed to determine odds ratio (OR) for good outcome and mortality in $\geq 80$ years age group after controlling for baseline variables. All analyses were performed using SPSS v25 software (IBM Corporation, New York).

\section{Results}

Between January 2015 and March 2018, 151 patients aged $\geq 80$ years and 273 patients aged 60-79 years received IValteplase via the MUSC Health TS program. The mean age was 86.6 years for the older age group (range 80-98 years) and 69.5 years for the younger age group (Table 1). The older age group had more women (70\% in $\geq 80$ years vs. $51 \%$ in $60-79$ years; $p=0.0002$ ) and a higher mean NIHSS on presentation (11.9 in $\geq 80$ years vs. 9.4 in $60-79$ years; $p=0.0012$ ). The older age group had more aphasic patients compared with younger patients based on NIHSS score of $\geq 1$ point for language $(63.1 \%$ in $\geq 80$ years vs. $43.7 \%$ in 60-79 years; $p=0.002$ ). The two groups did not differ in the percentage of patients with a normal level of awareness per the NIHSS score of LOC1a of 0 points on presentation ( $88 \%$ in $\geq 80$ years vs. $89.3 \%$ in $60-79$ years; $p=0.58$ ).

There was a nonsignificant trend toward earlier activation of TS alert in older patients ("ED-door-to-TS-consult-page" mean time of $17.4 \mathrm{~min}$ in $\geq 80$ years vs. $20.8 \mathrm{~min}$ in 60-79 years; $p=0.058$ ). The TS consultant neurologists took more time to determine IV-alteplase candidacy in the older age group ("TS-consultant-login-to-alteplase-decision" time of $22.1 \mathrm{~min}$ in $\geq 80$ years vs. $19.3 \mathrm{~min}$ in $60-79$ years; $p=0.01$ ). The final door to needle times were similar in both groups (57.1 $\mathrm{min}$ in $\geq 80$ years vs. $60.2 \mathrm{~min}$ in $60-79$ years; $p=0.24$ ).

With regard to safety, both groups had similar rates of sICH and aICH post-IV-alteplase (Table 2). At the end of hospital stay, 22\% of older patients were discharged home compared with $41 \%$ of younger patients $(p=0.001)$ (Table 2). A more significant percentage of older patients died during the hospitalization $(15 \%$ in $\geq 80$ years vs. $6 \%$ in $60-79$ years; 


\begin{tabular}{|c|c|c|c|}
\hline BASELINE VARIABLE & $\begin{array}{l}\geq 80 \\
\text { YEARS }\end{array}$ & $\begin{array}{l}60-79 \\
\text { YEARS }\end{array}$ & $\mathbf{p}$ \\
\hline Total number & 151 & 273 & \\
\hline Age, mean (SD), years & $86.6(4.53)$ & $69.5(5.86)$ & $<0.001$ \\
\hline Females, $n(\%)$ & $106(70)$ & $140(51)$ & 0.0002 \\
\hline NIHSS, mean (SD) & $11.9(7.4)$ & $9.4(7.7)$ & 0.0012 \\
\hline \multicolumn{4}{|l|}{ NIHSS-LOC1a score, $n(\%)$} \\
\hline 0 & $132(88)$ & 243 (89.3) & 0.58 \\
\hline 1 & $10(6.7)$ & $21(7.7)$ & \\
\hline 2 & $5(3.3)$ & $6(2.2)$ & \\
\hline 3 & $3(2)$ & $2(0.7)$ & \\
\hline \multicolumn{4}{|l|}{ Aphasia (based on NIHSS score), $n(\%)$} \\
\hline No & $55(36.9)$ & $152(56.3)$ & 0.002 \\
\hline Yes & $94(63.1)$ & $118(43.7)$ & \\
\hline $\begin{array}{l}\text { Symptom onset to ED door time, } \\
\text { mean (SD), min }\end{array}$ & $75.3(51.6)$ & $77.3(52.6)$ & 0.71 \\
\hline $\begin{array}{l}\text { ED door to TS consult page time, } \\
\text { mean (SD), min }\end{array}$ & $17.4(16.5)$ & $20.8(18.1)$ & 0.058 \\
\hline $\begin{array}{l}\text { Consult page to TS } \\
\text { consultant login time, } \\
\text { mean (SD), min }\end{array}$ & $4.3(2.8)$ & $4.3(3.5)$ & 0.97 \\
\hline $\begin{array}{l}\text { ED door to TS consultant login time, } \\
\text { mean (SD), min }\end{array}$ & $21.6(17.1)$ & $25.6(20.8)$ & 0.0448 \\
\hline $\begin{array}{l}\text { TS consultant login to alteplase } \\
\text { decision time, mean (SD), min }\end{array}$ & $22.1(14.6)$ & $19.3(9.4)$ & 0.01 \\
\hline $\begin{array}{l}\text { Door to needle time, } \\
\text { mean (SD), min }\end{array}$ & $57.1(26.9)$ & $60.2(27.3)$ & 0.24 \\
\hline $\begin{array}{l}\text { Symptom onset to needle time, } \\
\text { mean (SD), min }\end{array}$ & $131.6(57.6)$ & $137.4(57.2)$ & 0.32 \\
\hline $\begin{array}{l}\text { Alteplase decision to alteplase } \\
\text { administration time, } \\
\text { mean (SD), min }\end{array}$ & $15(14.2)$ & $16(13.8)$ & 0.53 \\
\hline
\end{tabular}

ED, emergency department; LOC, level of consciousness; NIHSS, National Institutes of Health Stroke Scale; SD, standard deviation; TS, telestroke.

$p=0.004)$ or were discharged to hospice care $(11 \%$ in $\geq 80$ years vs. $1 \%$ in 60-79 years; $p=0.001$ ) compared with younger patients. At 90 days, the older age group had a significantly lower number of patients with a good functional outcome $(39.1 \%$ in $\geq 80$ years vs. $74 \%$ in $60-79$ years; $p=0.001)$ as well as higher mortality (38\% in $\geq 80$ years vs. $14 \%$ in 60-79 years; $p=0.001$ ) (Table 3). After controlling for gender, NIHSS, and door to needle times, the OR for good

\section{Table 2. Outcomes}

OUTCOME $\geq 80$ YEARS

Symptomatic $\mathrm{ICH}, n(\%)$

\begin{tabular}{l|c|c|c}
\hline Yes & $6(4)$ & $13(5)$ & 0.81 \\
\hline No & $103(68)$ & $174(64)$ & \\
\hline Missing & $42(28)$ & $86(31)$ & \\
\hline
\end{tabular}

Asymptomatic $\mathrm{ICH}, n(\%)$

\begin{tabular}{l|c|c|c}
\hline Yes & $19(13)$ & $23(9)$ & 0.22 \\
\hline No & $84(58)$ & $161(62)$ & \\
\hline Missing & $42(29)$ & $76(29)$ & \\
\hline
\end{tabular}

Confirmed diagnosis, $n(\%)$

\begin{tabular}{l|c|c|c}
\hline Ischemic stroke & $102(68)$ & $164(60)$ & 0.31 \\
\hline Stroke-mimic & $10(7)$ & $24(9)$ & \\
\hline Missing & $39(25)$ & $85(31)$ & \\
\hline
\end{tabular}

Discharge disposition, $n(\%)$

\begin{tabular}{l|c|c|c}
\hline Home & $34(22)$ & $111(41)$ & $<0.001$ \\
\hline Rehab & $25(17)$ & $40(15)$ & \\
\hline Nursing home & $12(8)$ & $12(4)$ & \\
\hline Hospice & $16(11)$ & $4(1)$ & \\
\hline Death & $23(15)$ & $17(6)$ & \\
\hline Missing & $41(27)$ & $89(33)$ & \\
\hline
\end{tabular}

$\mathrm{ICH}$, intracranial hemorrhage.

functional outcome was 0.20 (95\% CI: $0.12-0.34 ; p<0.001$ ) and the OR for mortality was 4.26 (95\% CI: 2.42-7.49; $p<0.001$ ) in the older cohort.

\section{Discussion}

To the best of our knowledge, this is the largest cohort of octogenarians and nonagenarians who received IV-alteplase after remote evaluation by a neurologist via TS. The older age group was observed to have more women and higher NIHSS on presentation than the younger age group. These trends are similar to other studies, which compared $\geq 80$-year-old acute ischemic stroke patients with $<80$-year-old patients in traditional setting. ${ }^{13-16}$

There is a trend toward earlier TS consult request by the emergency departments, and the "ED-door-to-TS-consult-MDlogin" time is significantly shorter for the older age group. This difference, however, is being balanced by the longer time taken by TS consultant to conclude candidacy for IV-alteplase leading to similar "door to needle" times in both groups. 
Table 3. 90-Day Functional Outcomes

\begin{tabular}{|l|c|c|c}
\multicolumn{1}{|c|}{ FUNCTIONAL OUTCOME } & $\geq \mathbf{8 0}$ YEARS & $\mathbf{6 0 - 7 9}$ YEARS & $\mathbf{p}$ \\
\hline Good outcome (mRS 0-2), $n(\%)$ & $59(39.1)$ & $202(74)$ & 0.001 \\
\hline Mortality (mRS 6), $n(\%)$ & $58(38)$ & $39(14)$ & 0.001 \\
\hline
\end{tabular}

mRS, modified Rankin Scale.

To our knowledge, no other study has highlighted such an observation. We believe that this noteworthy observation can be explained by increased awareness of the higher incidence of cerebrovascular diseases in elderly by the emergency department physicians and staff leading to sooner activation of TS consultation. The relatively longer time for evaluation is likely multifactorial and can include factors such as presence of more aphasic patients leading to delays in performance of neurological examination remotely via TS and higher prevalence of cognitive impairment in $\geq 80$-year-old patients requiring inclusion of family members in obtaining history and decision-making process to ensure that the time from symptom onset to treatment conforms to the current guidelines. Although our database does not include the stroke etiology, more aphasic patients in the older age group can be explained by greater prevalence of larger cortical strokes from cardioembolic etiology and lower prevalence of small vessel etiology in older patients compared with younger patients. ${ }^{17-19}$

No significant difference was observed with regard to sICH between the two groups. This observation is consistent with studies comparing sICH in IV-alteplase-treated $\geq 80$-year-old patients and $<80$-year-old patients in the traditional face-toface evaluation setting. ${ }^{3,15}$ The percentage of patients with a good outcome at 90 days was significantly lower in the older age group compared with the younger age group. Table 4 compares the outcomes of $\geq 80$-year-old IV-alteplase-treated patients after going through traditional face-to-face evaluation by a neurologist in the emergency department. Most of these studies were published in early to mid-2000s. While the patients with good functional outcomes at 90 days are similar

\begin{tabular}{|c|c|c|c|c|c|c|c|c|}
\hline \multirow[b]{2}{*}{ AUTHOR } & \multirow[b]{2}{*}{ SOURCE } & \multirow[b]{2}{*}{$N$} & \multirow[b]{2}{*}{$\begin{array}{l}\text { MEAN AGE } \\
\text { (YEARS) }\end{array}$} & \multirow[b]{2}{*}{$\begin{array}{l}\text { WOMEN } \\
(\%)\end{array}$} & \multirow[b]{2}{*}{$\begin{array}{l}\text { NIHSS } \\
\text { (MEAN) }\end{array}$} & \multicolumn{2}{|c|}{ CLINICAL OUTCOME } & \multirow[b]{2}{*}{ SICH (\%) } \\
\hline & & & & & & GOOD, \% & $\begin{array}{c}\text { DEAD } \\
\text { (MRS 6), \% }\end{array}$ & \\
\hline Ford et al. ${ }^{15}$ & SITS-ISTR & 1,831 & 83 & 59.3 & 14 & mRS 0-2, 35.2 & 30.2 & $\begin{array}{l}9.5 \text { (NINDS) } \\
1.8 \text { (SITS-MOST) }\end{array}$ \\
\hline Purroy et al. ${ }^{21}$ & Multicenter registry & 1,189 & 85 & 60.1 & 13 & mRS 0-2, 38.7 & 23.2 & 4.7 (SITS MOST) \\
\hline Sylaja et al. ${ }^{3}$ & $\begin{array}{l}\text { Canadian Alteplase for Stroke } \\
\text { Effectiveness Study (CASES) }\end{array}$ & 270 & 84.7 & 63 & 16 & mRS 0-1, 25.9 & 35.3 & 4.4 (NINDS) \\
\hline Toni et al. ${ }^{22}$ & Multicenter registry & 41 & 83 & 63 & $\begin{array}{c}13.5 \\
\text { (median) }\end{array}$ & mRS $0-2,44$ & 34.1 & 4.8 (ECASS II) \\
\hline van Oostenbrugge et al. ${ }^{23}$ & Single-center registry & 45 & 85 & 60 & NR & mRS $0-1,27$ & 40 & 11.1 (NINDS) \\
\hline Engelter et al. ${ }^{24}$ & Multicenter registry & 38 & 84 & 63 & 14.1 & mRS 0-1, 29 & 32 & 13 (NINDS) \\
\hline Chen et al. ${ }^{25}$ & Single-center registry & 56 & 84 & 55 & 18 & NR & 20 at discharge & 7.1 (ECASS II) \\
\hline Ringleb et al. ${ }^{26}$ & Single-center registry & 90 & 83 & 62 & 13 & mRS 0-1, 19 & 29 & 6.7 (NINDS) \\
\hline Tanne et al. ${ }^{27}$ & Multicenter survey & 30 & 85 & 50 & NR & NR & 20 at discharge & 3 (NINDS) \\
\hline Berrouschot et al. ${ }^{28}$ & Multicenter registry & 38 & 83 & 60.5 & 16 & mRS 0-2, 31.6 & 21.1 & 2.6 (ECASS II) \\
\hline Our study & MUSC Health TS database & 151 & 86.6 & 70 & 11.9 & mRS 0-2, 39.1 & 38 & 4 (NINDS) \\
\hline
\end{tabular}

sICH definitions: NINDS (any hemorrhage on CT scan within $36 \mathrm{~h}$ of thrombolysis with NIHSS increase by at least 1 point); SITS-MOST (parenchymal hematoma-2 on CT scan within $36 \mathrm{~h}$ of thrombolysis with NIHSS increase by at least 4 points); ECASS II (any hemorrhage on CT scan within $36 \mathrm{~h}$ of thrombolysis with NIHSS increase by at least 1 point).

CT, computed tomography; ECASS, European Cooperative Acute Stroke Study; MUSC, Medical University of South Carolina; NINDS, National Institute of Neurological Disorders and Stroke; NR, not reported; sICH, symptomatic intracranial hemorrhage; SITS-ISTR, Safe Implementation of Treatment in Stroke International Stroke Treatment Registry; SITS-MOST, Safe Implementation of Treatment in Stroke-Monitoring Study. 


\section{GIROTRA ET AL.}

in our cohort and those described in Table 4, the mortality at 90 days appears to be higher in our TS-treated patients than some of the reported outcomes in other studies. Higher utilization of hospice and palliative care in elderly patients with strokes in the U.S. over the recent years could attribute to some of the difference in the mortality rate in our study compared with most of the other studies, which were published over 10 years ago; however, further studies are encouraged to compare mortalities in elderly patients treated with IV-alteplase via TS to validate our observation. ${ }^{20}$

\section{LIMITATIONS}

Our study has several limitations. The study is nonrandomized and retrospective. The etiology of the stroke, cause of death, and complications occurring during the hospital stay are not included in the database. Inherent limitations of obtaining $\mathrm{mRS}$ at 90 days over telephonic interview cannot be overstated. Approximately $20-30 \%$ of the missing 90 -day mRS and hemorrhagic conversion rates are the most significant limitations in our study. Given that only $45 \%$ of patients were transferred to the MUSC, we have to rely on other primary and comprehensive stroke centers to obtain data on post-IValteplase complications, final diagnosis, and disposition status at discharge. Because of this, there is a sizable portion of data missing in these variables and underlines an important requirement of implementing quality controls to ensure spoke sites have acceptable training and resources to obtain various quality metrics at par to the national standards.

In conclusion, our findings suggest that $\geq 80$-year-old patients treated with IV-alteplase after remote evaluation via TS have poorer outcomes than 60- to 79-year-old patients, but importantly, the rates of sICH and aICH are similar in the two groups. Compared with traditionally evaluated $\geq 80$-year-old patients treated with IV-alteplase, our patients had similar rates of a good functional outcome, but a higher mortality rate.

\section{Disclosure Statement}

No competing financial interests exist.

\section{REFERENCES}

1. Kissela BM, Khoury JC, Alwell K, Moomaw CJ, Woo D, et al. Age at stroke: Temporal trends in stroke incidence in a large, biracial population. Neurology 2012;79:1781-1787.

2. Toni D, Ahmed N, Anzini A, Lorenzano S, Brozman M, Kaste M, et al. Intravenous thrombolysis in young stroke patients: Results from the SITS-ISTR. Neurology 2012;78:880-887.

3. Sylaja PN, Cote R, Buchan AM, Hill MD, et al. Thrombolysis in patients older than 80 years with acute ischaemic stroke: Canadian Alteplase for Stroke Effectiveness Study. J Neurol Neurosurg Psychiatry 2006;77:826-829.

4. Garcla-Caldentey J, Alonso de Lecinana $M$, Simal $P$, et al. Intravenous thrombolytic treatment in the oldest old. Stroke Res Treat 2012;2012:923676.
5. Müller-Barna P, Hubert GJ, Boy S, Bogdahn U, et al. TeleStroke units serving as a model of care in rural areas. 10-year experience of the TeleMedical project for integrative stroke care. Stroke 2014;45:2739-2744.

6. Al Kasab S, Adams RJ, Debenham E, Jones DJ, Holmstedt CA. Medical University of South Carolina Telestroke: A Telemedicine Facilitated Network for Stroke Treatment in South Carolina-A Progress Report. Telemed J E Health 2017;23: 674-677.

7. Kulcsar M, Gilchrist S, George MG. Improving stroke outcomes in rural areas through telestroke programs: An examination of barriers, facilitators, and state policies. Telemed J E Health 2014;20:3-10.

8. Al Kasab S, Orabi MY, Harvey JB, Turner N, Ayesse P, Debenham E, Holmstedt CA. Rate of symptomatic intracerebral hemorrhage related to intravenous TPA administered over telestroke within 4.5-hour window. Telemed J E Health 2018;24:749-752.

9. Kepplinger J, Barlin K, Deckert S, Scheibe M, Bodechtele U, Schmitt J. Safety and efficacy of thrombolysis in telestroke: A systematic review and metaanalysis. Neurology 2016;87:1344-1351.

10. Adams RJ, Debenham E, Chalela J. Chimowitz M. Hays A, Hill C, et al. REACH MUSC: A telemedicine facilitated network for stroke: Initial operational experience. Front Neurology 2012;3:33.

11. Almallouhi $E_{1}$ Holmstedt CA, Harvey J, Reardon C, Guerrero WR, et al. Long-term functional outcome of telestroke patients treated under drip-and-stay paradigm compared with patients treated in a comprehensive stroke center: A single center experience. Telemed J E Health 2019;25: 724-729.

12. Boan AD, Feng WW, Ovbiagele B, Bachman DL, Ellis C, Adams RJ, et al. Persistent racial disparity in stroke hospitalization and economic impact in young adults in the buckle of stroke belt. Stroke 2014;45:1932-1938.

13. Saposnik G, Cote R, Phillips S, Gubitz G, Bayer N, Minuk J, et al. Stroke outcome in those over 80. A multicenter cohort study across Canada. Stroke 2008;39: 2310-2317.

14. Naess $H$, Gjerde $G$, Waje-Andreassen U. Ischemic stroke in patients older and younger than 80 years. Acta Neurol Scand 2014;129:399-404.

15. Ford GA, Ahmed N, Azevedo E, Grond M, Larrue V, et al. Intravenous alteplase for stroke in those older than 80 years old. Stroke 2010;41:25682574.

16. Kammersgaard LP, Jorgensen HS, Reith J, Nakayama H. Pedersen PM, et al. Short- and long-term prognosis for very old stroke patients. The Copenhagen Stroke Study. Age Ageing 2004;33:149-154.

17. Nacu A, Fromm A, Sand KM, et al. Age dependency of ischaemic stroke subtypes and vascular risk factors in western Norway: The Bergen Norwegian Stroke Cooperation Study. Acta Neurol Scand 2016;133:202-207.

18. Bejot $Y$, Caillier M, Ben Salem D, Couvreur G, Rouaud O, et al. Ischaemic stroke subtypes and associated risk factors: A French population based study. J Neurol Neurosurg Psychiatry 2008;79:1344-1348.

19. Arboix A, Miguel M, Ciscar E, Garcia-Eroles L, Massons J, Balcells M. Cardiovascular risk factors in patients aged 85 or older with ischemic stroke. Clin Neurol Neurosurg 2006;108:638-643.

20. Singh T, Peters SR, Tirschwell DL, Creutzfeldt CJ. Palliative care for hospitalized patients with stroke: Results from the 2010 to 2012 national inpatient sample. Stroke 2017;48:2534-2540.

21. Purroy $F$, Vena $A$, Canovas $D$, Cardona $P$, Cocho D, Cuadrado-Godia $E$, et al. Influence of hospital type on outcomes of individuals aged 80 and older with stroke treated using intravenous thrombolysis. J Am Geriatr Soc 2017;65: E117-E122.

22. Toni D, Lorenzano S, Agnelli G, Guidetti D, Orlandi G, Semplicini A, et al. Intravenous thrombolysis with rt-PA in acute ischemic stroke patients aged older than 80 years in Italy. Cerebrovasc Dis 2008;25:129-135.

23. van Oostenbrugge RJ, Hupperts RMM, Lodder J. Thrombolysis for acute stroke with special emphasis on the very old: Experience from a single Dutch centre. J Neurol Neurosurg Psychiatry 2006;77:375-377. 


\section{OUTCOMES IN ELDERLY OVER TELESTROKE}

24. Engelter ST, Reichhart M, Sekoranja L, Georgiadis D, Baumann A, Weder B, et al. Thrombolysis in stroke patients aged 80 years and older: Swiss survey of IV thrombolysis. Neurology 2005;65:1795-1798.

25. Chen $\mathrm{Cl}$, Iguchi $Y$, Grotta JC, Garami Z, Uchino K, Shaltoni H, Alexandrov AV. Intravenous TPA for very old stroke patients. Eur Neurol 2005;54:140-144.

26. Ringleb $P A$, Schwark Ch, Kohrmann $M$, Külkens $S$, Jüttler $E$, Hacke W, Schellinger PD. Thrombolytic therapy for acute ischaemic stroke in octogenarians: Selection by magnetic resonance imaging improves safety but does not improve outcome. J Neurol Neurosurg Psychiatry 2007;78:690-693.

27. Tanne $D$, Gorman MJ, Bates VE, Kasner $S E$, Scott $P$, Verro P. Intravenous tissue plasminogen activator for acute ischemic stroke in patients aged 80 years and older: The tPA stroke survey experience. Stroke 2000;31:370-375.

28. Berrouschot J, Röther J, Glahn J, Kucinski T, Fiehler J, Thomalla G. Outcome and severe hemorrhagic complications of intravenous thrombolysis with tissue plasminogen activator in very old ( $\geq 80$ Years) stroke patients. Stroke 2005;36: 2421-2425.
Address correspondence to:

Tarun Girotra, MD

Department of Neurology

University of New Mexico

2211 Lomas Boulevard NE 2ACC

Albuquerque NM 87106

E-mail: tagirotra@salud.unm.edu

Received: November 17, 2018

Revised: December 15, 2018

Accepted: December 19, 2018

Online Publication Date: February 26, 2019 